\title{
STRATEGI RANTAI PASOK UDANG VANAME STUDI KASUS PADA PT. ARYAZZKA INDOPUTRA KABUPATEN ACEH BESAR
}

\author{
(Supply Chain Strategy Vanname Shrimp Study Cases in PT. Aryazzka Indoputra \\ Kabupaten Aceh Besar)
}

\author{
Ilham Syahputra ${ }^{1}$,Elly Susanti ${ }^{1}$, Lukman Hakim $^{1 *}$ \\ ${ }^{1}$ Program Studi Agribisnis, Fakultas Pertanian, Universitas Syiah Kuala
}

\begin{abstract}
Abstrak Tujuan penelitian ini yaitu untuk mengidentifikasi rantai pasok pada PT. Aryazzka Indoputra serta merumuskan strategi alternatif untuk perkembangan PT.Aryazzka Indoputra. Berdasarkan metode analisis deskriptif kualitatif menggunakan kerangka kerja yang di modofikasi oleh Vorst, hasil penelitian menujukkan bahwa kondisi manajemen ratai pasok pada PT. Aryazzka Indoputra dalam tahapan perkembangan. Hasil analisis FSCM menggambarkan struktur jaringan, manajemen rantai, proses bisnis, dan kinerja rantai pasok, dalam tahapan berkembang dan berjalan dengan baik, akan tetapi kondisi sumberdaya manusia, sumberdaya fisik, sumberdaya teknologi, dan sumberdaya modal yang dimiliki oleh PT. Aryazzka Indoputra masih perlu dibenahi dengan baik. Berdasarkan hasil matrik IFE dengan total nilai sebesar 3,079 dan pada matrik EFE memilki total nilai sebesar 3,528 diperoleh gambaran posisi rantai pasok saat ini dalam pemetaan kuadran matrik IE menetapi posisi dalam bagian sel I. Hal ini menggambarkan bahwa rantai pasok udang vaname berada pada posisi Growth, yang merupakan strategi memfokuskan perusahaan dalam suatu lini yang telah menjadi pilihan perusahaan untuk dikembangkan. Perumusan strategi rantai pasok untuk PT. Aryazzka Indoputra berdasarkan analisis IFE, EFE, IE, dan SWOT, dan QSPM, mendapatkan beberapa strategi yang menarik, strategi yang sangat menarik merupakan strategi (W dan T), yaitu : Mempererat hubungan kerjasama antara perusahaan dengan SDM yang ada, dan mempererat hubungan kerjasama anatara setiap anggota rantai pasok yang terlibat. Guna menyatukan seluruh anggota rantai pasok sehingga produk yang dihasilkan dan didistribusikan dengan waktu yang tepat, jumlah yang tepat sehingga dapat meminimalisir harga dan dapat memenuhi kebutuhan konsumen lokal dan luar negeri.
\end{abstract}

Kata Kunci: Strategi Rantai Pasok, Udang Vanname

\begin{abstract}
The purpose of this study is to identify supply chain at PT. Aryazzka Indoputra and formulate alternative strategies for the development of PT.Aryazzka Indoputra. Based on qualitative descriptive analytical method using framework modified by Vorst, the result of research shows that the condition of management of supply at PT. Aryazzka Indoputra in the development stage. FSCM analysis results describe the network structure, chain management, business process, and supply chain performance, in the stage of developing and running well, but the condition of human resources, physical resources, technological resources, and capital resources owned by PT. Aryazzka Indoputra still needs to be improved. Based on the IFE matrix results with a total value of 3,079 and in the EFE matrix having a total value of 3.528 the current supply chain position description in the IE quadrant matrix mapping resides in the cell position I. This illustrates that the vanname shrimp supply chain is in the Growth position, which is a strategy of focusing the company in a line that has become the company's choice to be developed. The formulation of supply chain strategy for PT. Aryazzka Indopura based on the analysis of IFE, EFE, IE, and SWOT, and QSPM, get some interesting strategy, a strategy that is very interesting is the strategy (W and T), namely: Strengthening partnerships between companies with existing HUMAN RESOURCES, and strengthening of relations of cooperation between all members of the supply chain involved. In order to unite all members of the supply chain so that products that are produced and distributed in a timely manner, the right amount so as to minimize the price and can meet the needs of local and overseas consumers.
\end{abstract}

Keywords: Supply Chain Strategy, Vanname Shrimp.

\section{PENDAHULUAN}

Indonesia merupakan Negara kepulauan yang memiliki sumberdaya laut yang melimpah. Sektor perikanan merupakan salah satu sektor yang penting dalam pertumbuhan ekonomi Indonesia. Sebagian besar sumbangan devisa Negara merupakan sektor perikanan,

*Corresponding author: lukman.hakim.sp.mp@unsyiah.ac.id 
dimana sektor perikanan budidaya menyerap 38,35\% angkatan kerja nasional hal ini menunjukkan bahwa sektor perikanan budidaya sangat berperan penting dalam peningkatan kesejahteraan masyarakat Indonesia.

Udang vaname (Litopenaeus vannamei) merupakan salah satu komoditi unggulan perikanan pasar nasional maupun pasar internasional. Pada tahun 2013, Indonesia baru memproduksi udang vanname sebesar 500.000 ton/tahun. Hasil tersebut belum mencukupi semua kebutuhan pasar dunia maka pada tahun 2014 target produksi udang vanname ditingkatkan menjadi 699.000 ton/tahun agar dapat memenuhi kebutahan pasar dunia (Derktoral Jendral Perikana Budidaya dalam Erlando et al., 2015). Keberhasilan dalam sebuah usaha dicapai apabila rantai kegiatan dari mulai penyediaan bahan baku hingga produk sampai ketangan konsumen akhir terkelola dengan baik, pengelolaan rantai pasok ini dikenal dengan istilah Manajemen Rantai Pasok. Manajemen rantai pasok memberikan suatu mekanisme yang mengatur proses bisnis, meningkatkan produktivitas dan mengurangi biaya operasional perusahaan. Pengelolaan rantai pasok dalam agroindustri di definisikan sebagai hubungan kerjasama antara produsen, pengolah serta pedagang ritel dalam memberikan jaminan serta meminimalkan biaya produksi (Brown dalam Triyanti, R \& Yusuf.R, 2015).

Pengelolaan rantai pasok dalam agroindustri di definisikan sebagai hubungan kerjasama antara produsen, pengolah serta pedagang ritel dalam memberikan jaminan serta meminimalkan biaya produksi (Brown dalam Triyanti, R \& Yusuf.R 2015). Namun sampai saat ini belum banyak lembaga yang melakukan interverensi menyeluruh pada semua rantai pasok. Perbaikan dalam praktek budidaya dan peningkatan kualitas tidak diikuti dengan peningkatan akses terhadap pasar untuk mendapatkan harga dan margin keuntungan yang lebih baik. Pemasaran melalui pedagan besar mengalamipasang surut dari segi keberlanjutan bisnis.

PT. Aryazzka Indoputra merupakan salah satu penghasil atau produsen udang vanname yang berlokasi di Desa Ladong, Kabupaten Aceh Besar. Dimana kondisi manajemen rantai pasok pada PT. Aryazzka Indoputra masi belum terorganisir dengan baik, dimana penerapan GAP / SOP masi dalam proses dan dari segi eksternalnya belum tersedianya kelempok tani, belum tersedianya kelembagaan perikanan, penyuluhan, penelitian dan prasarana coldstroge, maka perlu dilakukan pengelolaan rantai pasok yang baik, agar dapat memenuhi kebutuhan konsumen dan mempunyai keunggulan yang kompetitif untuk pada usaha ini. Dimana perusahaan di tuntut agar dapat mengatur dan dapat mengelola aliran rantai pasok yang terjadi agar berjalan dengan baik dan sesuai harapan. Oleh karena itu PT.Aryazzka Indoputra perlu dilakukan penelitian untuk mengkaji pengelolaan rantai pasok yang terjadi pada perusahaan dan lingkungan terkait. Berdasarkan penjelasan dan fakta tersebut, uraian masalah yang akan dikaji yaitu: Bagaimana kondisi rantai pasok pada PT. Aryazzka Indoputra. dan Strategi rantai pasok apa yang tepat terhadap perkembangan PT. Aryazzka Indoputa. Tujuan penelitian ini, mengidentifikasi rantai pasok pada PT. Aryazzka Indoputra, dan merumuskan strategi alternatif untuk perkembangan PT.Aryazzka Indoputra

\section{METODE PENELITIAN}

Metode penelitian yang digunakan pada penelitian ini adalah anlisis deskriptif kualitatif menggunakan kerangka kerja yang dimodofikasi oleh Vorst. Setelah menggunakan analisis deskriptif kualitatif maka selanjutnya adalah melakukan tahapan analisis strategi. 
Teknik pengumpulan data dilakukan dengan cara pengumpulan data primer dan data skunder. Data primer dan data skunder didapat dari data internal dan eksternal PT. Aryazzka Indoputra. Data primer didapat dari wawancara dan kuisioner dengan pihak perusahaan yaitu manajer utama, dan manajer pemasaran. Data skunder yang digunakan bertujuan untuk mendukung data primer. Data yang bersifat internal dapat diperoleh dari studi pustaka, laporan penjualan, harga bahan baku, dan lain sebagainya.

\section{Analisis Penelitian}

\section{Analisis Formulasi Strategi}

\section{Matrik Perencanaan Strategi Kuantitatif (Quantitative Strategic Planning Matrix)}

\section{a. Penentuan Bobot}

Penentuan bobot dilakukan dengan jalan mengajukan identifikasi faktor strategi internal dan eksternal tersebut kepada pihak manajemen atau pakar dengan metode paired comparison (Kinnear and Taylor, 1991, dalam Setiawan, 2011).

Metode tersebut digunakan untuk memberikan penilaian terhadap setiap faktor penentu internal dan eksternal. Penentuan bobot setiap variabel digunakan skala 1, 2, dan 3.

Adapun keterangan dari setiap skalanya adalah :

$1=$ Jika indikator horizontal kurang signifikan daripada indikator vertikal

$2=$ Jika indikator horizontal sama signifikan daripada indikator vertikal

$3=$ Jika indikator horizontal lebih signifikan daripada indikator vertikal

Bobot setiap variabel dapat diperoleh dengan menentukan nilai setiap variabel dengan menggunakan rumus :

$$
a_{i}=\frac{X_{i}}{\sum_{i=1}^{n} X_{i}}
$$

Keterangan :

$$
\begin{aligned}
& \begin{array}{ll}
\mathrm{a}_{\mathrm{i}} & =\text { Bobot Variabel ke } \mathrm{i} \\
\mathrm{X}_{\mathrm{i}} & =\text { Nilai Variabel } \\
\mathrm{n} \text { faktor internal } & =\text { jumlah faktor internal } \\
\mathrm{n} \text { faktor eksternal } & =\text { jumlah faktor ekternal } \\
\mathrm{i} & =1,2,3, \ldots \ldots, \mathrm{n}
\end{array}
\end{aligned}
$$

\section{b. Matrik IFAS}

Menganalisis lingkungan internal untuk mengetahui informasi dari dalam perusahaan yang meliputi manajemen, budaya dan sumberdaya organisasi. Langkah-langkah penggunaan IFAS (Wheelen dan Hunger, 2012).

1. Kekuatan dan kelemahan dituliskan dengan nilai masing-masing 5-10 pada kolom 1 
2. Bobot masing-masing faktor dari 1.0 (paling signifikan sampai) 0.0 (tidak signifikan) pada kolom 2 berdasarkan pengaruh yang mungkin muncul dari faktor tersebut terhadap posisi strategi perusahaan. Bobot total harus berjumlah 1.0 .

3. Rating masing-masing faktor dimulai dari 5 (sangat baik ) sampai 1 (sangat buruk) pada kolom 3 berdasarkan respon perusahaan terhadap faktor tersebut.

4. Bobot masing-masing faktor dikalikan dengan ratingnya untuk mendapatkan skor terbobot dari masing-masing faktor pada kolom 4.

5. Kolom 5 (keterangan) digunakan dalam pemakaian yang masuk akal terhadap setiap faktor.

6. Skor terbobot ditambahkan untuk mendapatkan skor terbobot total untuk perusahaan pada kolom 4. Hal ini menginformasikan bagaimana perusahaan merespon faktor-faktor strategi di dalam lingkungan internalnya.

\section{c. Matrik EFAS}

Menganalisis lingkungan ekternal untuk mengetahui informasi dari luar perusahaan yang meliputi aspek ekonomi, sosial, budaya, politik, pemerintahan, hukum, teknologi, pesaing, pelanggan dan pangsa pasar.

Langkah-langkah dalam penggunaan EFAS (Wheelen dan Hunger, 2012).

1. Peluang-peluang dan ancaman-ancaman dituliskan dalam angka 5 sampai dengan 10 pada kolom 1.

2. Bobot setiap faktor diberi nilai 1.0 (paling signifikan) sampai dengan 0.0 (tidak signifikan) dalam kolom dua berdasarkan kemungkinan pengaruh suatu faktor tehadap posisi strategi organisasi. Bobot total harus berjumlah 1.00 kolom 2 .

3. Nilai setiap faktor diberi nilai dari 5 (baik sekali) sampai dengan 1 (buruk) sesuai respon perusahaan terhadap fator-faktor tersebut.

4. Setiap bobot faktor dengan ratingnya dikalikan untuk memperoleh setiap skor yang telah dibobotkan bagi setiap faktor di kolom 4 .

5. Kolom 5 (keterangan) digunakan untuk menjelaskan kegunaan pada setiap faktor.

6. Skor yang telah dibobotkan ditambahkan untuk memperoleh total skor yang telah dibobotkan pada organisasi di kolom 4. Hal ini menunjukanseberapa baik organisasi menanggapi faktor-faktor strategi dalamlingkungan eksternalnya.

\section{Analisis IE}

Analisis IE didasarkan pada dua dimensi kunci yaitu: total rata-rata IFE yang diberi bobot pada sumbu $x$ dan total rata-rata EFE yang diberi bobot pada sumbu y. Dari total rata-rata yang diturunkan dari masing-masing divisi, dapat disusun matriks IE pada tingkat korporasi. Pada sumbu $x$, total rata-rata IFE yang diberi bobot 1,01,99 menunjukkan posisi nilai internal yang lemah. Nilai 2,0-2,99 dianggap menengah, dan nilai dari 3,0-4,0 dianggap kuat (David, 2006).

1) Bagian yang masuk dalam bagian I, II dan IV merupakan kondisi tumbuh dan membangun. Strategi yang digunakan adalah strategi intensif (penetrasi pasar, pengembangan pasar dan pengembangan produk) atau strategi integrative (intregasi ke depan, intregasi ke belakang dan integrasi horizontal). 
2) Bagian yang masuk dalam bagian III, V dan VII merupakan strategi pertahanan dan pelihara. Strategi yang banyak digunakan adalah penetrasi pasar dalam pengembangan pasar.

3) Bagian yang masuk dalam bagian VI, VIII dan IX merupakan kondisi yang tidak menguntungkan. Strategi yang digunkan adalah strategi defensif (divestasi dan likuidasi).

\section{Matrik SWOT}

Matrik yang digunakan pada tahap pencocokan adalah matrik SWOT, yang ditujukan untuk merumuskan sejumlah alternatif strategi yang dapat diterapkan oleh rantai pasok. Terdapat 4 tahapan untuk membentuk matriks SWOT, yaitu :

1. Kekuatan internal rantai pasok disesuaikan dengan peluang eksternal untuk mendapatkan strategi SO.

2. Kekuatan internal rantai pasok disesuaikan dengan ancaman eksternal untuk mendapatkan strategi ST.

3. Kelemahan internal rantai pasok disesuaikan dengan memanfaatkan peluang eksternal untuk mendapatkan strategi WO.

4. Kelemahan internal rantai pasok disesuaikan dengan ancaman eksternal untuk mendapatkan strategi WT.

\section{Matrik QSPM}

Quantitative Strategic Planning Matriks (QSPM) adalah alat yang direkomendasikan bagi para ahli strategi untuk melakukan evaluasi pilihan strategi alternatif secara objektif, berdasarkan key success faktor internal dan eksternal yang telah diidentifikasi sebelumnya.

\section{HASIL PENELITIAN DAN PEMBAHASAN}

\section{Model Rantai Pasok Udang Vanname}

Model rantai pasok udang vaname pada PT. Aryazzka Indoputra antara lain : jumlah pelaku rantai pasok, karakteristik produk yang dihasilkan, jarak lokasi budidaya dan pasar, dan peran yang dimiliki oleh setiap pelaku rantai pasok. Model rantai pasok udang vanname pada PT. Aryaazka Indoputra dapat di lihat pada gambar 5.

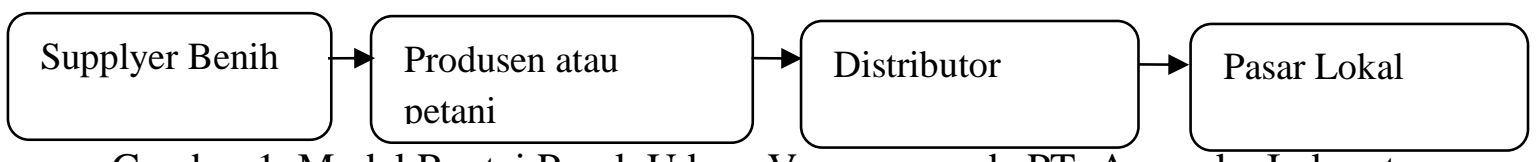

Gambar 1. Model Rantai Pasok Udang Vanname pada PT. Aryazzka Indoputra

\section{Manajemen Rantai Perusahaan}

\section{a. Kesepakatan Kontraktual}

Tujuan kerjasama dalam waktu jangka panjang umumnya di buat dalam kesepakatan kontraktual, dimana dengan terbentuknya kerjasama atau kemitraan, maka diharapkan agar semua anggota rantai pasok agar dapat mengoptimasi penggunaan 
sumberdaya nya guna mencapai keuntungan yang maksimal dan meminimumkan resiko,sehinnga anggota rantai pasok yang terlibat dalam kontraktual dapat berkembang.

\section{b. Sistem Transaksi}

Sistem transaksi yang diterapkan oleh para pelaku rantai pasok meliputi sistem cash atau faktur penjualan. Untuk produsen benih dengan perusahaan proses transaksi pada umumnya dilakukan dengan cara cash atau dengan cara membayar langsung kepada penjual benih guna mendapatkan barang secara langsung.

\section{c Pemilihan Mitra}

Pemilihan mitra dalam rantai pasok perusahaan bertujuan untuk menjamin proses kerjasama agar saling menguntungkan. Pihak yang dijadikan mitra dalam rantai pasok harus memenuhi kriteria yang telah ditentukan oleh pihak-pihak yang terlibat didalamnya.

\section{Analisis Lingkungan Eksternal}

Analisis faktor eksternal perusahaan salah satu tahapan untuk memperoleh peluang serta ancaman yang akan dihadapi oleh rantai pasok.

\section{Analisis lingkungan makro}

a. Faktor Hukum dan Politik

Faktor hukum yang berhubungan dengan kegiatan usaha budidaya udang vaname tidak lepas dari peraturan dan kebijakan pemerintah yang mempengaruhi kondisi politik dan keamanan negara. Seperti halnya program pemerintah dalam membantu pengembangan usaha budidaya udang vaname yang meliputi pemberian modal, pelatihan, penyuluhan, dan bantuan subsidi alat-alat usaha melalui dinas terkait. Pengenalan teknologi baru dan cara buddiaya yang baik sehingga menjadi peluang yang besar dan sangat baik bagi setiap anggota rantai pasok.

\section{b. Faktor Ekonomi}

Inflasi yang sering terjadi di Indonesia menyebabkan kondisi ekonomi yang tidak stabil, sehingga berdampak sangat buruk bagi pelaku usaha udang vaname, terjadinya inflasi yang tinggi menyebabkan kenaikan bahan baku dan harga jual yang tinggi, serta kondisi iklim yang cenderung tidak stabil menyebabkan pelaku usaha menjadi tidak stabil dalam memproduksi udang vaname.

\section{c. Sosial, Budaya dan Demografi}

Faktor sosial masyarakat merupakan salah satu faktor yang berpengaruh pada jalannya sebuah usaha, diamana perubahan gaya hidup masyarakat yang saat ini menerapkan suatu pola hidup yang sehat dengan mengkonsumsi makanan yang sehat. Hal ini membuat mayarakat memilih produk yang sehat, bergizi tinggi, dan steril dari penyakit. Sehinnga masyarakat menuntut produsen untuk menyediakan produk yang berkualitas tinggi, terjamin untuk di konsumsi, ramah lingkungan dan harga yang terjangkau.

\section{d. Faktor Teknologi}

Sistem teknologi yang digunakan saat ini oleh setiap anggota rantai pasok masih menggunakan sistem konvensional. Hal ini merupakan sebuah ancaman bagi rantai pasok, yang dimana pada proses penyimpanan dan perindustrian masih menggunakan es sebagai pendingin, seharusnya untuk saat ini sudah menggunakan teknologi yang modern seperti menguunakan mobil yang memiliki pendingin khusus guna menjaga kesegaran dan kualitas udang.

\section{Analisis lingkungan Mikro :}




\section{a. Ancaman produk pengganti}

Udang merupakan salah satu komoditi perikanan yang memiliki banyak jenisnya maka dari itu selain pesaing yang sejenis ada juga pesaing non sejenis, seperti udang tiger, udang galah, udang windu, dan lobster. Hal ini merupakan sebuah ancaman yang berat bagi rantai pasok udang vanname karena banyaknya produk pengganti, dengan adanya produk pengganti maka konsumen semakin lebih selektif dalam membeli maka dari itu tentunya akan menurunkan pangsa pasar udang vanname dipasaran.

b. Ancaman Pendatang Baru

Tumbuhnya perusahaan-perusahaan baru mengakibatkan implikasi pada penurunan pangsa pasar. Hal ini merupakan anacaman yang sangat berat bagi seta perusahaan untuk masuk kedalam industri. Hambatan masuk industri yang tinggi merupakan sebuah ancaman bagi rantai pasok udang vanname, karena untuk membuka sebuah perusahan baru diperlukan skala ekonomi yang relatif besar, serta tergantung pangsa pasar sasaran yang akan dituju. Sehingga dengan demikian hal tersebut merupakan salah satu hambatan bagi pendatang baru untuk dapat memulai usaha budidaya udang vaname.

c. Ancaman Persaingan Perusahaan Baru

Ancaman persaingan antara perusahaan baru cenderung kompetitif, dimana bisa dilihat dari jumlah pesaing baru yang semakin bertambah. Tingginya persaingan antara perusahaan, yang dimana perusahaan mampu menghasilkan produk yang berkualitas, melakukan inovasi baru, menjaga kepercayaan konsumen yang mampu menguatkan posisi dalam industri.

\section{Analisis IFE}

Tabel 1. Analisis IFE

\begin{tabular}{lccc}
\multicolumn{1}{c}{ Faktor Internal } & Bobot & Ranting & $\begin{array}{c}\text { Bobot } \\
\text { skor }\end{array}$ \\
\hline $\begin{array}{l}\text { Lokasi dekat dengan pasar } \\
\text { Komitmen dan kepercayaan antara pelaku rantai }\end{array}$ & 0,123 & 4 & 0,492 \\
pasok yang tinggi & 0,123 & 3 & 0,369 \\
$\begin{array}{l}\text { Tersedianya banyak lahan } \\
\text { Hubungan bisnis yang terjalin dengan baik antara }\end{array}$ & 0,137 & 4 & 0,101 \\
pelaku rantai pasok & 4 & 0,404 \\
$\begin{array}{l}\text { Belum adanya keterbukaan informasi antara pelaku } \\
\text { rantai pasok }\end{array}$ & 0,118 & 4 & 0,472 \\
$\begin{array}{l}\text { Alat yang digunakan masih tegolong tradisonal } \\
\text { Terbatasnya modal }\end{array}$ & 0,137 & 2 & 0,274 \\
Manajemen usaha yag masi kurang baik & 0,130 & 3 & 0,390 \\
$\quad$ Total & 0,130 & 1 & 0,130 \\
\hline
\end{tabular}

Dari hasil analisis IFE pada tabel 1 menyatakan faktor yang menjadi kekuatan utama di perusahaan Aryazzka Indoputra adalah tersedianya banyak lahan, dengan nilai bobot skor 0,548, namun memiliki kelemahan utama adalah manajemen usaha yang masi kurang baik dengan nilai bobot skor 0,130. Jumlah total bobot skor sebesar 3,079 yang menunjukkan bahwa rantai pasok perusahaan Aryazzka Indoputra memiliki posisi internal yang kuat, dimana telah mampu menggunakan kekuatan guna mengatasi kelemahan dengan cukup baik. 
Analisis EFE

Tabel 2. Analisis EFE

\begin{tabular}{|c|c|c|c|}
\hline Faktor Eksternal & Bobot & Ranting & Bobot \\
\hline $\begin{array}{l}\text { 1. Kebijakan program pemerintah yang mendukung } \\
\text { usaha }\end{array}$ & 0,128 & 4 & 0,512 \\
\hline 2. Harga yang tinggi dan stabil & 0,114 & 4 & 0,456 \\
\hline 3. Perubahan pola hidup masyarakat & 0,135 & 3 & 0,405 \\
\hline 4. Kondisi agroklimatologi yang mendukung & 0,114 & 3 & 0,342 \\
\hline 5. Hambatan masuk industri yang tinggi & 0,114 & 4 & 0,456 \\
\hline 6. Inflasi yang terjadi & 0,1 & 4 & 0,4 \\
\hline 7. Teknologi yang masi sederhana & 0,092 & 3 & 0,276 \\
\hline 8. Persaingan yang tinggi & 0,114 & 4 & 0,456 \\
\hline 9. Banyaknya produk pengganti & 0,085 & 3 & 0,255 \\
\hline Total & 1,761 & 31 & 3,528 \\
\hline
\end{tabular}

Dari hasil analisis EFE pada tabel 2 menyatakan faktor yang menjadi peluang utama di PT. Aryazzka Indoputra adalah kebijakan program pemerintah yang mendukung usaha, dengan nilai bobot skor 0,512, tetapi memiliki ancaman utama yaitu banyaknya produk pengganti dengan nilai bobot skor 0,255. Jumlah total bobot skor sebesar 3,528 yang menunjukkan bahwa rantai pasok di PT. Aryazzka Indoputra mampu memanfaatkan peluang yang ada guna mengatasi ancaman.

Tahapan Pencocokan Hasil Analisis Lingkungan IFE dan Lingkungan EFE

Tabel 3. Hasil Analisi IE

\begin{tabular}{|c|c|c|c|c|}
\hline & \multicolumn{3}{|c|}{ Total nilai IFE yang diberi bobot } \\
\hline & & $\begin{array}{c}\text { Kuat } \\
3,0-4,0\end{array}$ & $\begin{array}{c}\text { Rata-rata } \\
2,0-2,99\end{array}$ & $\begin{array}{c}\text { Lemah } \\
1,0-1,99\end{array}$ \\
\hline \multirow{3}{*}{$\begin{array}{c}\text { Total nilai } \\
\text { EFE yang } \\
\text { diberi } \\
\text { bobot }\end{array}$} & $\begin{array}{l}\text { Tinggi } \\
3,0-4,0\end{array}$ & I & II & III \\
\hline & $\begin{array}{c}\text { Sedang } \\
2,0-2,99\end{array}$ & IV & V & VI \\
\hline & $\begin{array}{c}\text { Rendah } \\
1,0-1,99\end{array}$ & VII & VIII & IX \\
\hline
\end{tabular}

Dari hasil anilisis IE diatas menggambarkan bahwa kondisi rantai pasok perusahaan menempati posisi pada bagian sel I A. Dimana bagian sel I A ini menunjukkan bahwa kondisi rantai pasok perusahaan pada posisi kuadran I A Rapid Growth, merupakan strategi yang memfokuskan perusahaan dalam satu lini yang telah menjadi pilihan perusahaan untuk dikembangkan, meggunakan strategi intensif dan strategi integrative. Strategi intensif seperti; penetrasi pasar, pengembangan pasar, dan pengebangan produk. Strategi intergrative seperti; intergasi kedepan, intergrasi kebelakang, dan intergrasi horizontal. 


\section{Analisis SWOT}

Hasil analisis SWOT berdasarkan kekuatan dan kelemahan (faktor internal), peluang dan ancaman (faktor eksternal) bagi PT. Aryazzka Indoputra diformulasikan dengan alternatif strategi dengan menggunakan analisis SWOT dapat dilihat pada Tabel 4.

\section{Tabel 4. Hasil Analisis SWOT}

\begin{tabular}{|c|c|c|}
\hline & Kekuatan / (S) & Kelemahan / (W) \\
\hline IFE & $\begin{array}{l}\text { 1. Lokasi dekat dengan pasar } \\
\text { 2. Komitmen dan kepercayaan } \\
\text { antara pelaku rantai pasok yang } \\
\text { tinggi } \\
\text { 3. Tersedianya banyak lahan } \\
\text { 4. Hubungan bisnis yang terjalin } \\
\text { dengan baik antara pelaku rantai } \\
\text { pasok }\end{array}$ & $\begin{array}{l}\text { 1. Belum adanya } \\
\text { keterbukaan informasi } \\
\text { antara pelaku rantai } \\
\text { pasok } \\
\text { 2. Alat yang digunakan } \\
\text { masi tegolong } \\
\text { tradisonal } \\
\text { 3. Terbatasnya modal } \\
\text { 4. Manajemen usaha yag } \\
\text { masi kurang baik }\end{array}$ \\
\hline Peluang / (O) & $\begin{array}{c}\text { Strategi S-O } \\
(\mathrm{S} 1, \mathrm{S3}, \mathrm{S} 4, \mathrm{O1}, \mathrm{O}, \mathrm{O3}, \mathrm{O5}) \\
\end{array}$ & $\begin{array}{l}\text { Strategi W-O } \\
(\mathrm{W} 1, \mathrm{~W} 2, \mathrm{~W} 3,01,\end{array}$ \\
\hline 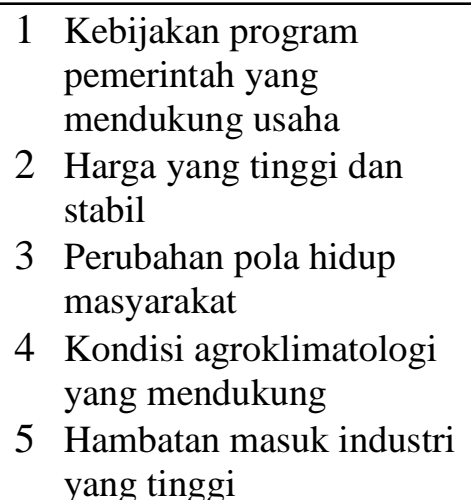 & $\begin{array}{l}\text { 1. Peningkatan jumlah produksi } \\
\text { dan kualitas mutu produk } \\
\text { 2. Peningkatan pelayanan atau } \\
\text { yolatiatas terhadap konsumen }\end{array}$ & $\begin{array}{l}\text { O2,O4) } \\
\text { 1. Peningkatan kualitas } \\
\text { SDM dan kinerja } \\
\text { SDM } \\
\text { 2. Menigkatkan produksi } \\
\text { dan kualitas produk } \\
\text { akhir }\end{array}$ \\
\hline Ancaman / (T) & $\begin{array}{c}\text { Strategi S-T } \\
(\mathrm{S} 1, \mathrm{S3}, \mathrm{S4}, \mathrm{T1}, \mathrm{T} 2, \mathrm{T3}, \mathrm{T5}) \\
\end{array}$ & $\begin{array}{c}\text { Strategi W-T } \\
\text { (W1, W2, W3,T1, T2, }\end{array}$ \\
\hline $\begin{array}{l}\text { 1. Inflasi yang terjadi } \\
\text { 2. Teknologi yang masih } \\
\text { sederhana } \\
\text { 3. Persaingan yang tinggi } \\
\text { 4. Banyaknya produk } \\
\text { pengganti }\end{array}$ & $\begin{array}{l}\text { 1. Meningkatkan pelayanan } \\
\text { konsumen } \\
\text { 2. Meningkatkan kualitas produk }\end{array}$ & $\begin{array}{l}\text { T3, T5) } \\
\text { 1. Meningkatkan } \\
\text { kerjasama antara } \\
\text { setiap anggota rantai } \\
\text { pasok udang vanname } \\
\text { 2. Meningkatkan } \\
\text { pelayanan distribusi } \\
\text { dan meminimalisir } \\
\text { margin pada setiap } \\
\text { rantai pasok. }\end{array}$ \\
\hline
\end{tabular}

\section{Strategi Strengh-Oppurtunity (S-O)}

Strategi S-O yaitu strategi yang memanfatkan kekuatan faktor internal perusahaan guna memanfaatkan peluang eskternal. Strategi alternatif yang dapat digunakan untuk strategi S$\mathrm{O}$ adalah : Menambahkan tingkat produksi produk pada tingkat produsen benih, guna pemenuhan tingkat konsumsi konsumen yang tinggi. Ini dapat dilakukan dengan 
memanfaatkan luas lahan yang ada dengan menggunakan pola budidaya secara intensif. Peningkatan mutu juga perlu dilakukan dan harus dijaga oleh produsen, tahapan ini dapat dialkukan saat sortir dan grading setelah pemanenan. Dengan demikian dapat meningkatkan kepuasan konsumen dari produk yang dihasilkan, sehingga konsumen semakin loyal pada produk yang dibelinya.

\section{Strategi Strenght-Threat (S-T)}

Strategi S-T yaitu strategi untuk mengurangi atau mencegah ancaman dari faktor eksternal guna menafaatkan ketkuatan-kekuatan faktor internal yang ada. Strategi yang dapat digunkan untuk strategi S-T adalah :

Meningkatkan pelayanan konsumen dan menjaga hubungan yang baik antara pelaku rantai pasok. Menjaga pelayanan terhadap konsumen oleh perusahaan sangatlah penting karena dapat memberikan yang terbaik untuk konsumen baik dari segi kualitas dan mutu produk.

\section{Strategi Wekness-Opportunity (W-O)}

Strategi W-O yaitu strategi untuk menggunakan peluang-peluang yang ada untuk mengatasi kelemahan-kelemahan yang dimiliki perusahaan. Strategi yang dapat digunkan untuk strategi W-O adalah : Meningkatkan kapasitas perusahaan dengan memanfaatkan kemampuan kerja sama tim dan pengalaman perusahaan guna memfokuskan kepada pertumbuhan dan perkembangan perusahaan dalam memaksimalkan produksi dan kualitas produk kepada konsumen.

\section{Strategi Wekness-Threat (W-T)}

Strategi W-T yaitu strategi yang digunakan untuk meminimalkan kelemahan serta menghindari ancaan yang akan dating. Strategi yang dapat digunakan untuk strategi W-T adalah Mempererat hubungan kerjasama antara perusahaan dengan SDM yang ada, dan mempererat hubungan kerjasama anatara setiap anggota rantai pasok yang terlibat. Guna menyatukan seluruh anggota rantai pasok sehingga produk yang dihasilkan dan didistribusikan dengan waktu yang tepat, jumlah yang tepat sehingga dapat meminimalisir harga dan dapat memenuhi kebutuhan konsumen lokal dan luar negeri.

\section{Analisis Quantitative Strategic Planing Matrix (QSPM)}

Dari hasil analisis maka dapat ditentukan strategi yang terbaik untuk dilaksanakan lebih utama dibandigkan dengan strategi lainnya adalah sebagai berikut :

Strategi 1 (W-O) yaitu : Meningkatkan kapasitas perusahaan dengan memanfaatkan kemampuan kerja sama tim dan pengalaman perusahaan guna memfokuskan kepada pertumbuhan dan perkembangan perusahaan dalam memaksimalkan produksi dan kualitas produk kepada konsumen.

Strategi 2 (S-T) yaitu : Meningkatkan pelayanan konsumen dan menjaga hubungan yang baik antara pelaku rantai pasok. Menjaga pelayanan terhadap konsumen oleh perusahaan sangatlah penting karena dapat memberikan yang terbaik untuk konsumen baik dari segi kualitas dan mutu produk. Oleh sebab itu para pelaku rantai pasok agar dapat menjaga hubungan dengan baik antara pelaku rantai pasok guna menciptakan keharmonisan dan kualitas, dan ketersediannya kuantitas yang baik. 
Strategi 3 (W-T) yaitu : Mempererat hubungan kerjasama antara perusahaan dengan SDM yang ada, dan mempererat hubungan kerjasama anatara setiap anggota rantai pasok yang terlibat. Guna menyatukan seluruh anggota rantai pasok sehingga produk yang dihasilkan dan didistribusikan dengan waktu yang tepat, jumlah yang tepat sehingga dapat meminimalisir harga dan dapat memenuhi kebutuhan konsumen lokal dan luar negeri.

Strategi 4 (S-O) yaitu : Menambahkan tingkat produksi produk pada tingkat produsen benih, guna pemenuhan tingkat konsumsi konsumen yang tinggi. Ini dapat dilakukan dengan memanfaatkan luas lahan yang ada dengan menggunakan pola budidaya secara intensif. Peningkatan mutu juga perlu dilakukan dan harus dijaga oleh produsen, tahapan ini dapat dialkukan saat sortir dan grading setelah pemanenan. Dengan demikian dapat meningkatkan kepuasan konsumen dari produk yang dihasilkan, sehingga konsumen semakin loyal pada produk yang dibelinya.

\section{SIMPULAN DAN SARAN}

\section{SIMPULAN}

Berdasarkan hasil analisis diskriptif kualitatif pada penelitian ini dengan mengunakan beberapa metode yaitu ; IFE, EFE, IE, dan SWOT, dan analisis QSPM, maka dapat disimpulkan sebagai berikut yaitu :

1. Kondisi manajemen ratai pasok pada PT. Aryazzka Indoputra dalam tahapan perkembangan dimana berdasarkan hasil analisis FSCM menggambarkan struktur jaringan, manajemen rantai, proses bisnis, dan kinerja rantai pasok, dalam tahapan berkembang dan berjalan dengan baik, akan tetapi kondisi sumberdaya manusia, sumberdaya fisik, sumberdaya teknologi, dan sumberdaya modal yang dimiliki oleh PT. Aryazzka Indoputra masih perlu dibenahi dengan baik.

2. Perumusan strategi rantai pasok untuk PT. Aryazzka Indoputra berdasarkan kesimpulan dari analisis IFE, EFE, IE, dan SWOT, dan QSPM, mendapatkan beberapa strategi yang menarik, strategi yang sangat menarik merupakan strategi ( $\mathrm{W}$ dan $\mathrm{T}$ ) dengan total nilai TAS : 6,459 yaitu : Mempererat hubungan kerjasama antara PT. Aryazzka Indoputra dengan anggota rantai pasok, dan mempererat hubungan kerjasama anatara setiap anggota rantai pasok yang terlibat. Guna menyatukan seluruh anggota rantai pasok sehingga produk yang dihasilkan dan didistribusikan dengan waktu yang tepat, jumlah yang tepat sehingga dapat meminimalisir harga dan dapat memenuhi kebutuhan konsumen lokal dan luar negeri.

\section{SARAN}

1. Sebaiknya PT. Aryazzka Indoputra harus memperhatikan kondisi manajemen tenaga kerja, dimana dari segi pertumbuhan perusahaan dapat dipengaruhi oleh kualitas SDM dan fasilitas yang dimilki oleh perusahaan.

2. Sebaiknya PT. Aryazzka Indoputra lebih memperhatikan dari segi informasi baik dari supplayer benih sampai pedagang ritel, agar dapat meningkatkan kepuasan konsumen. 


\section{DAFTAR PUSTAKA}

Anatan, L. \& L., Ellitan. 2008. Suplly Chain Management Teori dan Aplikasi. CV Alfabeta. Bandung.

Bramantyo, A. 2010. Manajemen Rantai Pasok Sayuran. IPB. Bandung.

Bryson, J. M. 2004. Strategic Planning for Public and Nonprofit Organizations: A Guide toStrengthening and Sustaining Organizational Achievement. 3rd Edition. San Francisco : Jossey-Bass.

Budidarsono, S., \& Indra, 2005. Survey Sosial Ekonomi pada Usaha Tambak di Aceh. ICRAF, Bogor

David, F. 2009. Strategic Management Concepts and Cases Ninth Edition. Prentice Hall, New Jersey.

Erlando. G. Rusliadi \& Mulyadi. 2015. Increasing Calcium Oxide (Cao) To Accelerate Moulting And Survival Rate Vannamei Shrimp (Litopenaeus vannamei). University of Riau.

Haliman, R.W. \& Adijaya, D. 2005. Udang Vannamei. Penebar Swadaya. Jakarta.

Haliman, R. W. \& Dian . A. S. 2006. Udang Vannamei. Penebar Swadaya. Jakarta.

Kurniawati, 2014. Manajemen Sumber Daya Manusia Di MiIstiqomah Sambas Purbalingga. Purwokerto.

Mahmoodi, M. Chizari. M. Kalantari. K. \& Eftekhari. A. R.. 2014.The Quantitative Strategic Planning Matrix (QSPM) Applied to Agri-Tourism : A Case Study in Coastal Provinces of Iran. Vol 2. Iran.

Marimin, M. N. 2010. Aplikasi Teknik Pengambilan Keputusan dalam Manajemen Rantai Pasok. Edisi Pertama.IPB Press. Bogor.

Marimin, M., A.D. Machfud, M. P.I.F.Putra. \& Bangkit, W. 2014. Value Chain Analysis for Green Productivity Improvement in the Natural Rubber Supply Chain. Jurnal of Cleaner Production.201-211.

Masoumi, E. Salarzehi. H. Arbatani. T. R. \& Dezhkam. J. 2015. Strategic analysis of Fishery industry development in Iran.Asian Journal of Research in Business Economics and Management.Vol 5. Iran.

Nugraha, A, C, 2011.Analisis Rumusan Strategi Rantai Pasokan Minyak Akar Wangi di Kabupaten Garut, Jawa Barat.

Ramadhan. A. G, 2013. Pengaruh Analisis SWOT Terhadap Keunggulan Sistem Manajemen Rantai Pasokan Pada PT. Misaja Mitra Pati Jawa Tengah. Fakultas Ekonomika Dan Bisnis Universitas Diponegoro .Semarang

Siagian, Y.M. 2005. Aplikasi Suplply Chain Management Dalam Dunia Bisnis.Grasindo. Jakarta.

Setiawan, D. 2011. Strategi Pengembangan Perikanan Tangkap Di Kabupaten Pacitan Berbasis Pada Distribusi Ikan yang Didaratkan Di Ppp Tamperan. Skripsi.

Fakultas Perikanan Dan Ilmu Kelautan, Institusi Pertanian Bogor.

Sugiman, F et,al. 2013. Pengembangan Bisnis di Lihatdari Faktor internal dan Ekseternal Perusahaan pada Homestay Dhanesvara di Surabaya, Surabaya.

Susyana, A. O. 2005. Analisis Rantai Persediaan (Supply Chain) Komoditas Jeruk Medan (Studi Kasus Di Pasar Induk Kramat Jati dan Carrefour Cempaka Mas, Jakarta) Skripsi.Fakultas Pertanian.Institut Pertanian Bogor. Bogor.

Triyanti, R. \& Yusuf.R 2015.Analisis Manajemen Rantai Pasok Lobster (Studi Kasus di Kabupaten Simeulue, Aceh). Balai Besar Penelitian Sosial Ekonomi Kelautan dan Perikanan. Jakarta Utara. 
Umar, Husein. 2003. Metodelogi Penelitian : Aplikasi Pemasaran. Jakarta: Gramedian Pustaka Utama..

Vander Vorst Jack GAJ. 2005. Effective food supply chains; generating,modeling and evaluating supply chain scenarios. Netherlands (NL). Jurnal Wageningen University.

Waters, D. 2007. Supply Chain Risk Management: Vulnerability and Resilience in logistics. Kogan Page Publishers. USA.

Wicaksono, D. A. 2010. Analisis Strategi Rantai Pasok Udang Vaname (Studi Kasus Petani Plasma Tambak Pandu Karawang, Kabupaten Karawang, Jawa Barat) Skripsi. Fakultas Pertanian. Institut Pertanian Bogor. Bogor.

Wheelen, T. L. \& H. J. David. 2012. Strategic Management and Business Policy : Toward Global Sustainability. Thirteen Edition. United States: Pearson.

Yolanda, C. Nurmalina. R dan Suharjo 2014. Rantai Pasok Brokoli di Kec Lembang dengan pendekatan FSCN. Skripsi. Institut Pertanian Bogor. Bogor.

Yulianti, D. 2014. AnalisisLingkungan Internal Dan Eksternal Dalam Pencapaian Tujuan Perusahaan (Studi Kasus Di Pt. Perkebunan Nusantara VII Lampung). Lampung. 